Publicación semestral No. 13 (2019) 1-10

\title{
Graciana de Acuña y Jaso: una criolla de noble cuna
}

\author{
Graciana de Acuña and Jaso a criolla of noble birth
}

María Esther Pacheco-Medina ${ }^{a}$

\begin{abstract}
:
Graciana de Acuña y Jaso, was a Creole woman of noble birth who lived at the beginning of the XVII century in Tulancingo, was the heir of the rich mayorazgo that her parents founded, Diego Suárez de Peredo and Doña María de Acuña and Jaso. He married very young with Don Luis de Vivero e Ircio, who would become the Second Count of the Orizaba Valley. They lived and formed a family in Tulancingo, a town where they left their mark. The family of Doña Graciana owned the house that would be known a century later as the famous tile house. This text explores the survivals of the presence of this woman in the Tulancingo Valley region.
\end{abstract}

Keywords:

Graciana, mayorazgo, family, legacy

Resumen:

Graciana de Acuña y Jaso, fue una mujer criolla de noble cuna que vivió a principios del siglo XVII en Tulancingo, fue la heredera del rico mayorazgo que fundaron sus padres, Diego Suárez de Peredo y Doña María de Acuña y Jaso. Se casó siendo muy joven con Don Luis de Vivero e Ircio, quien se convertiría en el Segundo Conde del Valle de Orizaba. Vivieron y formaron una familia en Tulancingo, población en la que dejaron huella de su presencia. La familia de Doña Graciana fue propietaria de la casa que se conocería un siglo más tarde como la famosa casa de los azulejos. Este texto indaga sobre las supervivencias de la presencia de esta mujer en la región del Valle de Tulancingo.

\section{Palabras Clave:}

Graciana, mayorazgo, familia, legado

\section{Desarrollo}

Algunos lugares, sin importar el tamaño de su población, resguardan grandes historias, como es el caso de la ciudad de Tulancingo. Esta pequeña ciudad, ubicada a escasos noventa kilómetros de la capital del país y a cuarenta de la capital del estado, ha sido testigo de muchos hechos que se relacionan con su patrimonio cultural.

Han sido varias las familias que han contribuido para el engrandecimiento de este lugar, algunos de sus aportes se han perdido en el tiempo, fueron víctimas del mal llamado "progreso", el cual ha despojado de su identidad a una gran parte de las ciudades del centro del país. En Tulancingo desaparecieron emblemáticos lugares como los portales que rodeaban la Plaza de la Constitución, mejor conocida como "La Floresta", la capilla de la Tercera Orden, que estaba ubicada en el atrio de la catedral y muchas viejas casonas ubicadas en el primer cuadro de la ciudad... 


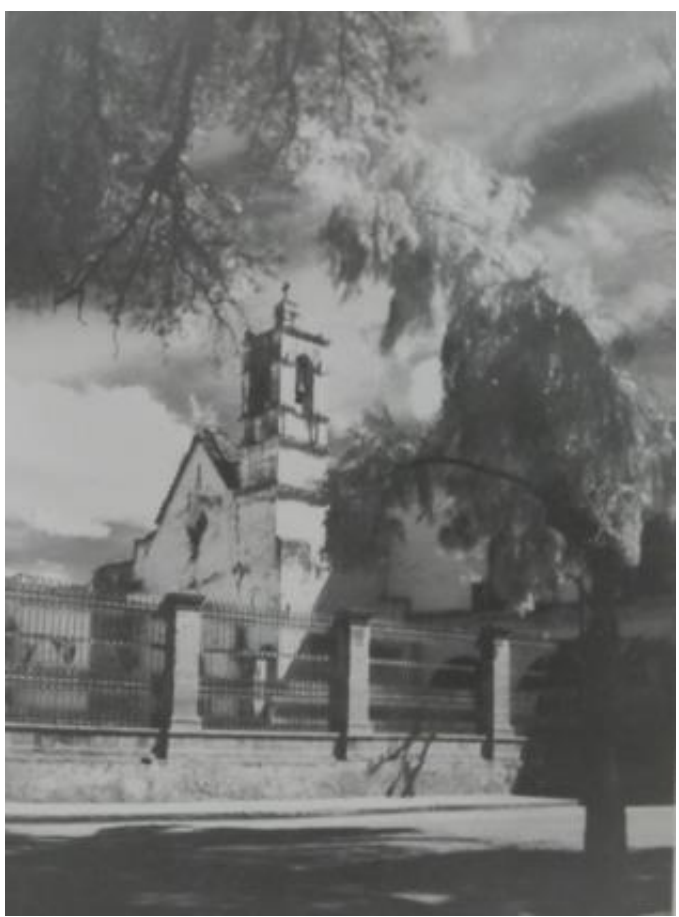

Imagen 1. Capilla de la Tercera Orden. S. XVI. Fotografía cortesía del Señor Ignacio Villegas.

En una de esas casas que han desaparecido, junto a la cual se ubicaba la plazuela conocida como "de la condesa", vivió una noble y adinerada familia que dejó su impronta en esta población. Su legado hoy en día, es conocido solamente por algunas personas que conocen a fondo la historia de Tulancingo.

Tulancingo a principios del siglo XVI conservaba su organización territorial prehispánica, basada en la división del calpultin, que más tarde se transformaría en barrios y parcialidades. Las dos parcialidades de Tulancingo era Tlaixpa (otomí) y Tlatoca (mexica), a las que estaban sujetos otros pueblos de la región.

En 1526 la encomienda de Tulancingo fue repartida entre Francisco Terrazas y Francisco de Ávila o Dávila. El primero de los cuales sirvió directamente bajo las órdenes de Cortés, como su mayordomo. El segundo fue uno de los primeros pobladores de la región. A Terrazas le correspondió la encomienda de Tlatoca y a Dávila de Tlaixpa.

La ubicación del lugar y lo benigno de su clima convirtió a Tulancingo en "retiro de antiguos conquistadores", pues muchos de los ex combatientes lo eligieron para vivir a pesar de su clasificación de "pueblo indígena". Sus servicios fueron recompensados con tierras que fueron destinadas a diversos cultivos y a la cría de ovejas y ganado vacuno y caprino. Las alianzas entre poderosas familias a través de matrimonios arreglados permitieron el engrandecimiento de estas posesiones, muchas de las cuales se escrituraron bajo la figura del mayorazgo. ${ }^{1}$ Una de estas familias asentadas en la región del Valle de Tulancingo fue la de Don Diego de Peredo Suárez y Doña María de Acuña y Jaso, quienes fundaron el Mayorazgo de Peredo Suárez-Acuña y Jaso a favor de su hija Graciana, quien se convertiría en la esposa de II Conde del Valle de Orizaba.

Graciana de Acuña y Jaso o Peredo Suárez- Acuña y Jaso, fue hija de don Diego de Peredo Suárez y de doña María de Acuña y Jaso. Era común en los siglos XVI y XVII que a las hijas se les conociera por el apellido de la madre y a los varones por el del padre. También era frecuente invertir el orden de los apellidos. Graciana nació alrededor del año 1600, hasta el momento no se conoce el lugar exacto en donde nació, aunque se sabe que sus padres tenían casas en la ciudad de México y Tulancingo. Le tocó nacer como se dice, en pañales de seda, pues sus padres eran propietarios de inmensas extensiones de tierras, que incluían estancias de ganado, ranchos y haciendas en una buena parte del Altiplano.

\footnotetext{
${ }^{1}$ Mayorazgo era un sistema de reparto de bienes, "la institución del mayorazgo impedía que las tierras de las familias nobles pudieran dividirse, ya que establecía que los herederos primogénitos eran los únicos que tenían derecho a heredarlas".
} 
Fernández de Recas, en su magna obra Mayorazgos de la Nueva España (1965:141-142), detalla que Doña María de Acuña y Jaso, otorgó una escritura con la autorización de su marido Diego de Peredo y Suárez para instituir el Mayorazgo de sus bienes el trece de febrero de 1608. Reinaba en ese entonces en España Felipe III, al cual solicita su autorización para la fundación del mayorazgo.

La escritura describe minuciosamente los bienes del matrimonio Peredo y Suárez-Acuña y Jaso, destacando las Casas principales que declaran como su morada, con los "altos y bajos y todo lo a ella anexo y perteneciente y la Plazeta que es la misma Casa, como consta por el Titulo de ella y compra de Fernando de Ávila que vendió a Luis de la Torre..."(Fernández de Recas, 1965:142). De acuerdo a la interpretación de Javier Sánchiz Ruiz (2017:63), dichas casas son las que posteriormente se conocerían como "la famosa casa de los azulejos" y el callejón al que se refiere la escritura es el de Dolores, conocido posteriormente como el de la Condesa. Sánchiz Ruiz, destaca en su obra El Condado del Valle de Orizaba a través de sus mujeres (2017), que dicho callejón no pudo haberse conocido así por nuestra Graciana, pues ella no llegó a ostentar el título de condesa, debido a que murió en 1623, trece años antes de que su marido heredara el título en 1636. Aun así, seguramente Doña Graciana fue conocida como la condesa en su círculo más cercano y en Tulancingo. La escritura del mayorazgo se modificó en dos ocasiones, en 1610 y en 1617 cuando Graciana ya se había casado con Don Luis de Vivero.

Graciana, fue una noble criolla, hija única de don Diego de Peredo y Suárez, natural de la ciudad de México y de su esposa doña María de Acuña y Jaso; don Diego pertenecía a la casa del marqués de Villena y del conde de Nieva; Doña María de Acuña y Jaso, hija legítima de Don Pedro de Acuña y de Doña Graciana de Jasso, era descendiente de Lorenzo Payo, uno de los primeros conquistadores de la Nueva España. Vincularon al mayorazgo las casas que poseían en la ciudad de México, con todo su bagaje, muebles, como un escritorio de Flandes, una cama de Damasco carmesí con las goteras de brocado; vajillas de plata dorada y blanca; armas, ocho arcabuzes.

Además de las casas y sus enseres, vincularon labores de riego localizados en Tacubaya; estancias de ganado mayor y menor en el Valle de México, en San Gerónimo, San Diego de Tepancingo junto a Apan y San Gerónimo cerca de Tepeapulco. Menciona además más de diez mil ovejas, seis mil cabras, cinco manadas de yeguas borradas y setenta burros, además de cerdos. (Recas, 1965:143)

El vínculo enumera tierras de labor, hacienda y estancias de ganado en Tultengo, Tezontepec, Tulancingo, Almoloya, Ocelotepec, Oztochichilco, Zacatlán, Tenancingo, Aculco, Huauchinango, Mazatepec, Hueyapan y otros cien más (Aguirre Beltrán, 1965:49).

La escritura nombra después a los esclavos negros pastores y especifica: "que nunca haya menos de doce vaqueros y seis pastores y seis cabreros" en cada hacienda. En la casa de la calle de San Francisco nueve esclavos domésticos, cinco de ellos mujeres, establece además que si alguno muriera debía sustituirse (Crf. Recas, 1965:145, 146).

Una tercera cláusula en la escritura del mayorazgo establece que los beneficiarios de este debían adoptar nombres y apellidos de los fundadores Diego y María; Suárez de Peredo y Acuña y Jaso.

De acuerdo a las costumbres de la época, doña Graciana contrajo matrimonio a temprana edad. Distintas fuentes consultadas afirman que las capitulaciones matrimoniales fueron firmadas en Orizaba el 23 de febrero de 1613, cuando ella tenía solo trece años y don Luis diecinueve y que el matrimonio religioso se celebró en Tulancingo el 19 de marzo de 1616 (Aguirre Beltrán, 1965:48). Las capitulaciones matrimoniales también se realizaron en la ciudad de México ante el escribano Antonio Gómez (Sánchiz, 2017: 61).

$\mathrm{Si}$ el matrimonio religioso se efectúo en Tulancingo, se habrían casado en la iglesia del convento franciscano. Sin embargo, hasta este momento aún no se ha localizado el acta de matrimonio en el archivo histórico, pero la búsqueda continua. 


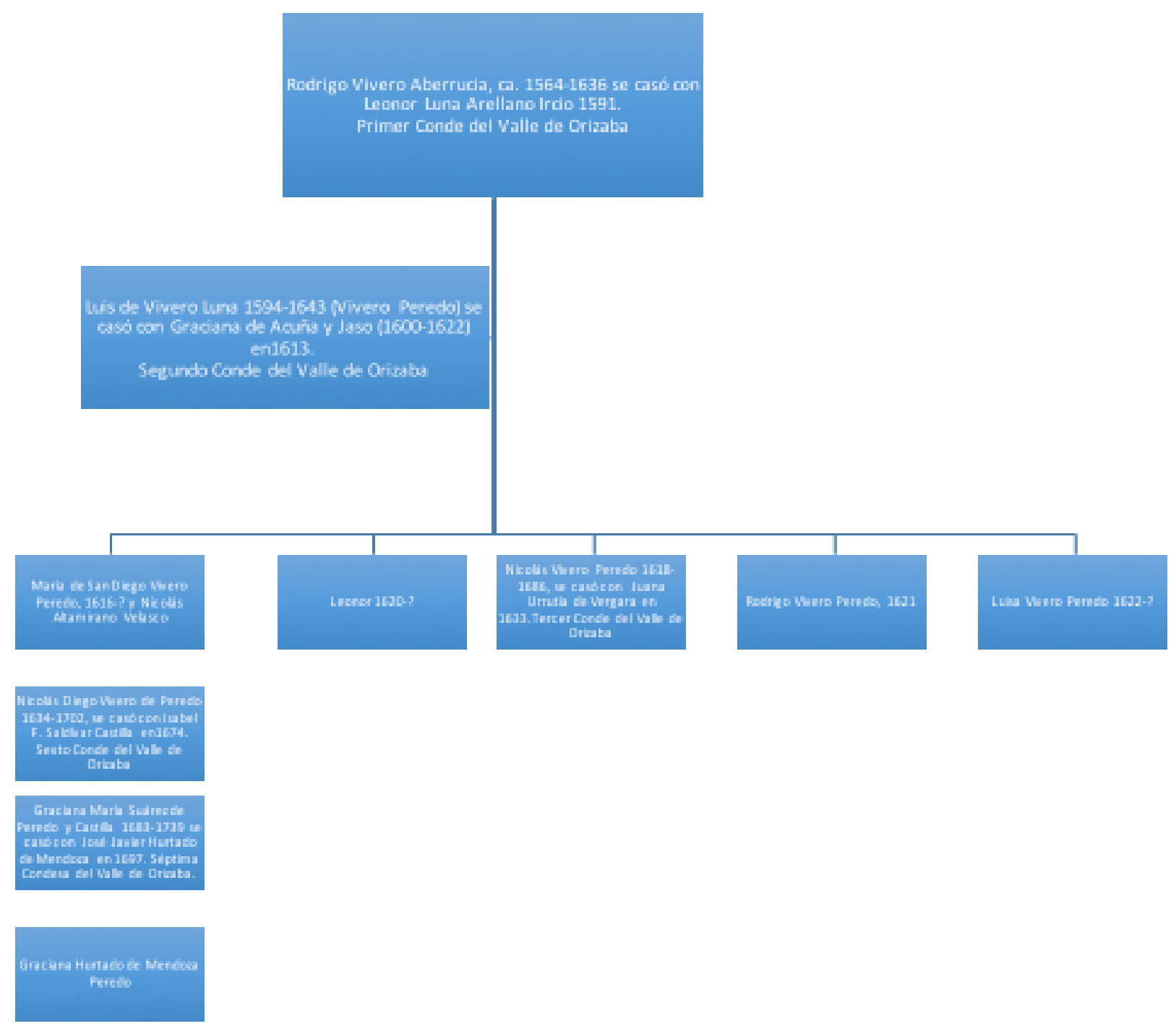

Cuadro 1 .

Doña Graciana aportó al matrimonio una dote de cien mil pesos; fue a partir de 1617 primera poseedora del Mayorazgo Suárez de Peredo, con imposición del apellido Peredo y sus armas, según se estipuló en las capitulaciones matrimoniales. El futuro Il conde del Valle de Orizaba se llamó desde entonces Luis de Vivero y Peredo (Conde y Díaz Rubín y Sánchiz Ruiz, 2012: 31).

De entre todas sus propiedades, doña Graciana y don Luis eligieron una de sus casas de Tulancingo para vivir. Algunas fuentes señalan que la casa donde vivieron estaba ubicada en la calle 21 de marzo (calle del Eco) entre las calles de Hidalgo (Acuario) y Primero de Mayo, y que existió junto a ella una plazuela que fue conocida como la "plaza de la condesa".

Las nobles familias criollas de la época, solían tener casas grandes, investigaciones como las realizadas por Martha Fernández y Gustavo Curiel nos permiten conocer a grandes rasgos la distribución de las habitaciones y las dependencias que solían tener las casas de estas familias adineradas. Una de las habitaciones más importantes era la sala para recibir visitas de cumplimento, esta habitación solía estar en la planta alta y tenía acceso directo al balcón principal. En esta sala se ubicaba el estrado de la señora de la casa, en este lugar la dueña de casa recibía formalmente a invitados de su mismo nivel social. El estrado estaba formado por tarimas de madera que se cubrían con alfombras traídas de ultramar. Un dato interesante es el que se refiere a la manera como solían sentarse las mujeres en este espacio, pues se sabe que solían utilizar cojines para hacerlo y que estos más tarde fueron sustituidos por taburetes, esto obedecía al tipo de vestido que 
usaban que no les permitía utilizar sillas. (Crf. Curiel, 2005: 82). Esta información permite deducir que la casa en donde vivieron don Luis de Vivero y Peredo debió contar con una sala similar en la que Doña Graciana recibiría a sus invitados y familiares. Los documentos del archivo histórico del antiguo convento que fueron consultados, contienen anotaciones en las que se señalan que fueron escogidos como padrinos de bautizo de los hijos de autoridades locales en varias ocasiones.

Otro espacio importante en las casas principales fue el Oratorio, para poder tener uno debía pagarse una licencia al arzobispado. Lo más común era que tuvieran un pequeño retablo o un tríptico que cumpliera esta función, debían tener una mesa que sirviera como altar para oficiar misa y espacios para guardar los ornamentos y los objetos utilizados en la celebración. Solía dedicarse al santo del que fuera devota la familia, se sabe que la familia de Doña Graciana, su padre en primer lugar, tenía una especial devoción por San Diego, por ser su santo patrono, como lo demuestra la capellanía que fundó en el convento de San Juan Bautista Tollantzingo para celebrar la fiesta de este santo cada doce de noviembre y de la que se siguieron haciendo cargo sus descendientes. Por lo que podemos pensar que este santo tendría un lugar especial en el oratorio de la casa de los Vivero Peredo. Gabriela Sánchez Reyes (2005:537), menciona que las casas de las familias nobles contaron con un oratorio en el que además de la celebración de la eucaristía, la familia rezaba diariamente el santo rosario, escribe además que en la casa de los condes del Valle de Orizaba conocida actualmente como de los Azulejos, se conserva aún la portada de la capilla, lo que refuerza nuestra hipótesis sobre la existencia de este espacio en la casa que perteneció a la misma familia que fue dueña de la ahora famosa casa de la antigua calle de San Francisco.

Un espacio muy especial debió ser el comedor, pues en este solía exhibirse el servicio de plata y oro propiedad de la familia. Fue común en esa época que toda familia de mediana posición contara con algunas piezas de plata, por lo que las ricas familias contaban con vajillas completas que solían mostrar en ocasiones especiales. En el caso de la familia de Graciana, los documentos consultados demuestran que al menos realizaron cuatro bautizos en la ciudad de Tulancingo, y estas serían las ocasiones especiales para lucir las vajillas y piezas de plata mencionadas en el inventario de sus bienes.

En las grandes casas y palacios de la nobleza novohispana fue costumbre que las parejas tuvieran habitaciones separadas, el mueble más importante en estas habitaciones era la cama, de grandes proporciones y que solía estar lujosamente adornada con colgaduras como las mencionadas en el inventario antes mencionado (cama de Damasco carmesí con goteras de brocado). A principios del siglo XVII se utilizaron camas de madera tallada y dorada, por lo que este debió ser el material de las camas de la casa de la plazuela de la condesa. También fue importante el espacio conocido como el Tocador, en este espacio se realizaba el arreglo personal de los miembros de la familia y solía estar cerca o junto a las recámaras. Este espacio nos dice Curiel tomó su nombre del mueble que allí se colocaba y que ya se menciona como tal en inventarios de principios del siglo XVII. Los baños y retretes solían ubicarse lejos de los aposentos debido al mal olor que producían.

Por otro lado, Martha Fernández (2005:53), menciona que, durante el siglo XVII, las azoteas también eran utilizadas para recibir visitas y que este era un espacio femenino. Referencias gráficas permiten constatar que las casas de esa época solían tener dos y hasta tres niveles por lo que la vista desde las azoteas debía ser extraordinaria, en el caso que nos ocupa, estando situada la casa tan cerca del convento y su iglesia, seguramente desde la azotea por el lado de la actual calle de Hidalgo podría contemplarse la huerta del convento, en la que se sabe había muchos nogales y desde la calle 21 de marzo, el inconfundible Cerro del Tezontle, con sus magueyeras y biznagas que hasta mediados del siglo pasado eran abundantes en el lugar.

Las casas de gente importante tenían al menos dos patios y aunque aún no se han localizado documentos que describan la casa que habitaron Graciana y Luis de Vivero en Tulancingo, fuentes posteriores mencionan que adyacente al espacio que ocupa actualmente el mercado municipal -espacio en el que se presume estaba ubicada la casa de Doña Graciana- existió una plazuela conocida como "de la condesa". En la ciudad de Tulancingo se conservan solo algunas casas antiguas, la mayoría de finales del siglo XIX y principios del XX, una de ellas, la de los Méndez, ubicada en la calle de Doria y que está prácticamente en ruinas, tenía dos patios, en el primero, alrededor del cual se ubicaban las habitaciones, existía una hermosa fuente en el centro y un jardín de estilo andaluz, en el segundo se ubicaban las dependencias de la servidumbre y las caballerizas. 
Solo podemos suponer que la elección se debió a que doña Graciana pudo haber estado apegada a esta casa y a esta población por haber crecido en Tulancingo. Su padre, don Diego, se firmaba como vecino de Tulancingo y fundó una capellanía en la antigua iglesia franciscana a favor de San Diego, su patrono, en la cual se estipulaba que para la fiesta del santo se pagaran doce pesos por la misa que se cante al santo cada doce de noviembre. Los herederos del mayorazgo heredaron esta responsabilidad, lo cual consta en documentos consultados en el Fondo franciscano de la Biblioteca del Museo Nacional de Antropología e Historia. ${ }^{2}$ Actualmente no existe ninguna imagen de San Diego expuesta en la catedral de Tulancingo, sin embargo, si existe un cuadro y una talla en madera del santo, aunque ambas se encuentran en lamentable estado (Cfr. Pacheco, 2013: 163).

En el archivo histórico del ex convento franciscano se han localizado las partidas de bautizo de cuatro de los cinco hijos del matrimonio, lo que confirma su arraigo en esta población. La de María de San Diego con fecha noviembre de 1616, Nicolás el 24 de junio de 1618, Leonor, el 17 de noviembre de 1620 y Rodrigo en septiembre de 1621 (Archivo Histórico Digital del Ex convento franciscano y Parroquia El Sagrario, Tulancingo, Hgo.). ${ }^{3}$ La partida de Luisa no fue localizada, podemos suponer que no nació en Tulancingo, sino probablemente en la ciudad de México por alguna complicación del embarazo que finalmente pudo costarle la vida a Graciana, pues esta murió entre el mes de mayo de 1623 y el de junio 1625. En el archivo del antiguo convento se ha localizado la partida de bautizo de un niño llamado Cristóbal, del que fueron padrinos de bautizo el 2 de mayo de 1623, don Luis de Vivero y Doña Graciana y en 1625, Don Luis inició el inventario de sus bienes.

Estudios como los realizados por María del Carmen León Cázares (2005: 28), nos permiten conocer la rutina cotidiana de la gente que vivió en los albores del siglo XVII en la ciudad de México y relacionarlo con lo que sucedería en Tulancingo en ese entonces. Sin duda, la salida a misa sería una de las actividades más importantes de la época y formaría parte de la rutina de la familia Vivero Peredo - Acuña y Jaso, cuya casona se encontraba muy próxima al convento y su iglesia. Años después el primer Conde del Valle de Orizaba recibió la autorización para llevar al templo, silla y cojín, como reconocimiento a su posición social. En la iglesia del antiguo convento franciscano debieron tener un lugar reservado para ellos, también se sabe que eran patronos de la capilla de San Diego que se ubicaba en este templo y la cual suponemos debió estar adosada al muro norte de la nave principal como se observa en algunas otras iglesias franciscanas del país. En la actual catedral de Tulancingo se distingue un acceso cegado en el muro norte que corresponde a las dimensiones que podía haber tenido una capilla lateral. Una fiesta muy importante en la población de Tulancingo era la de su santo patrono, San Juan Bautista, que se celebra el 24 de junio y que, hasta mediados del siglo XX, era la celebración religiosa más importante de este lugar. Los franciscanos designaron a este santo como patrono de esta población nombrándola San Juan Bautista Tollantzingo. Se sabe también a partir de diversos documentos localizados en el Fondo Reservado del Fondo franciscano de la Biblioteca del Museo Nacional de Antropología que existieron varias cofradías tanto de españoles como de indios en esta población, en cuyas fiestas y procesiones participarían los criollos nobles que vivían en este lugar; una de las importantes sería la del Corpus Christi. En Tulancingo existieron también cárceles del Santo Oficio, estaban ubicadas en las faldas del Cerro del Tezontle; aunque se han localizado documentos sobre diversos procesos no mencionan la celebración de Autos de fe.

En esta ciudad el día de plaza es el día jueves y se sabe por los relatos de cronistas como Mendieta, que a este tianguis "bajaban de la sierra y acudían desde lugares cercanos una gran multitud" para ofrecer sus productos y comprar diversos enseres que se vendían en Tulancingo todos los jueves. Seguramente la salida a la plaza debió ser una de las actividades que podría haber disfrutado la joven Graciana.

Que queda de una persona después de su muerte, cuál es su legado a esta población en la que seguramente vivió los años más felices de su corta vida. Los inventarios y los testamentos nos permiten atisbar en algunos aspectos de su vida. Su viudo ordenó hacer un inventario de sus bienes el $1^{\circ}$ de julio de 1625 y nombró como albacea de sus hijos menores a Pedro de Ontiveros y a Antonio de Mendoza, vecino de Tulancingo, se asume él mismo como vecino de esta población (Recas, 1965:63).

\footnotetext{
${ }^{2}$ FRBMNAH.FF. Documento 4017. Memorias de las obras pías de la tercera orden y convento de Tulancingo, [anónima, s.f., ca. 1754]. F. 283-288.

${ }^{3}$ Archivo Histórico digital del ex convento franciscano y Parroquia el Sagrario de Tulancingo, Hgo. Sección Sacramental/SSA Bautismos/0102. 
El Inventario de los bienes se realizó en Tulancingo ante Gerónimo Alemán, escribano local y firmaron como testigos vecinos de esta población. El documento se conserva en el Archivo General de la Nación. ${ }^{4}$

Dicho inventario se realizó durante varios días, en este trabajo me he concentrado principalmente en los bienes personales de doña Graciana, con el fin de intentar descifrar a esta joven mujer que vivió en Tulancingo a principios del siglo XVII.

Primero de julio, 1625/ Primeramente plata, menaje de casa (vajillas), muebles, menciona en particular dos escritorios uno japonés y otro alemán.

Tres de julio, 1625 /Primeramente doscientos quince botones de oro esmaltado, también cincuenta botones de oro y diamantes, también cien botones de oro acanalados, también doscientos cincuenta botones de plata, también ciento veinte broches de plata, una cadena de oro con doscientos diamantes, una banda de oro...,

Un vestido entero, basquiña y jubón de terciopelo negro, basquiña, jubón y espinal azul y negro.

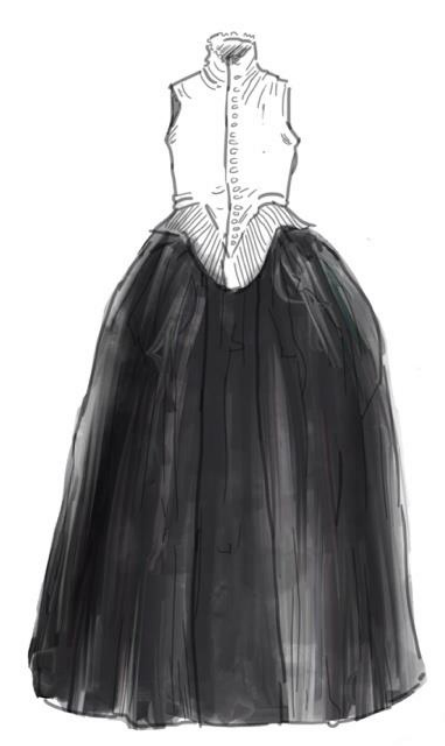

Imagen 2. Jubón y basquiña

Entre las numerosas posesiones que menciona el inventario, destaca por lo reducido, la descripción de las prendas de vestir, la ropa era un artículo de lujo en aquellos tiempos. Son numerosas en cambio las alhajas.

\footnotetext{
${ }^{4}$ Archivo General de la Nación/ Instituciones Coloniales/ Gobierno Virreinal/ Vínculos y Mayorazgos (115)) Volumen 36/Exp. 2.
} 


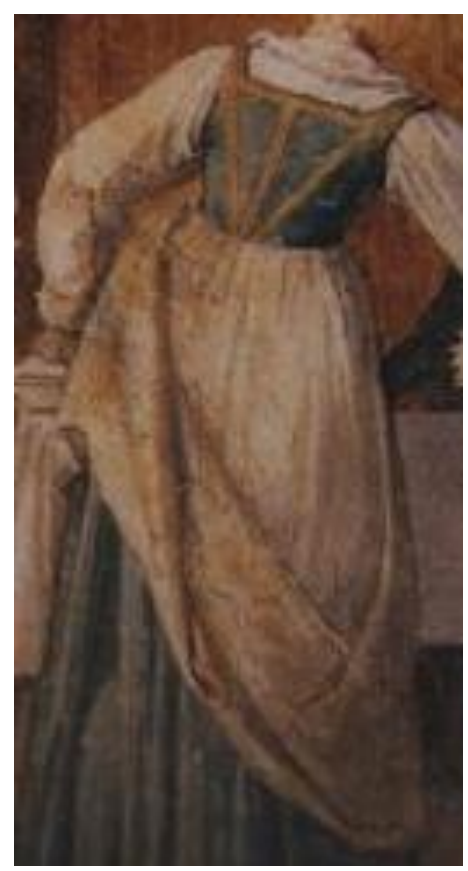

Imagen 3. Vestido de la época

Dada la posición del conde en su calidad de pariente de dos de los virreyes de la Nueva España y formando parte de la nobleza novohispana la pareja debió asistir con toda seguridad a una gran cantidad de festejos y ceremonias en la ciudad de México. En el archivo del antiguo convento también aparecen varias veces como padrinos de los hijos de algunos personajes importantes como el alcalde mayor de Tulancingo.

No era común en los albores del siglo XVII que se elaboraran retratos femeninos, en pleno auge del barroco, la temática era principalmente religiosa, por lo que tener una idea de cuál pudo ser la apariencia de nuestro personaje resultará solo aproximada. Existen retratos de personajes reales de este periodo vistiendo prendas descritas en el inventario, por lo que me atrevo a suponer que debió tener una apariencia similar a la de algunos de estos retratos

Sin embargo, resulta mucho más atractivo e íntimo pensar en ella como una mujer joven apegada a su familia, rodeada de sus pequeños hijos y luciendo un atuendo sencillo como los de las modelos de Bartolomé de Murillo, en los que la ropa se utiliza para destacar los rasgos de un rostro pícaro y risueño, como los de su obra "Mujeres en la ventana", que pintó alrededor de 1670 y que actualmente se encuentra en la Galería Nacional de Arte de Washington. Doña Graciana murió a los 23 años, su hija mayor, María tendría apenas seis años y Nicolás, el futuro III conde del Valle de Orizaba tan solo cuatro años.

¿Qué es lo que permanece de su presencia en Tulancingo?

El segundo hijo de Graciana de Acuña, el III conde del Valle de Orizaba Nicolás Vivero y Suárez de Peredo, murió en 1686, su viuda doña Juana de Urrutia donó en su nombre dos hermosas pinturas de indudable calidad, para la capilla de San Diego que existía en la vieja iglesia franciscana. Las pinturas se encuentran actualmente colocadas en el crucero de la catedral de esta ciudad. Este es el legado visible en esta población y que actualmente, tres siglos después de haber sido donadas, requieren de una restauración inmediata para detener el grave deterioro que sufren. 


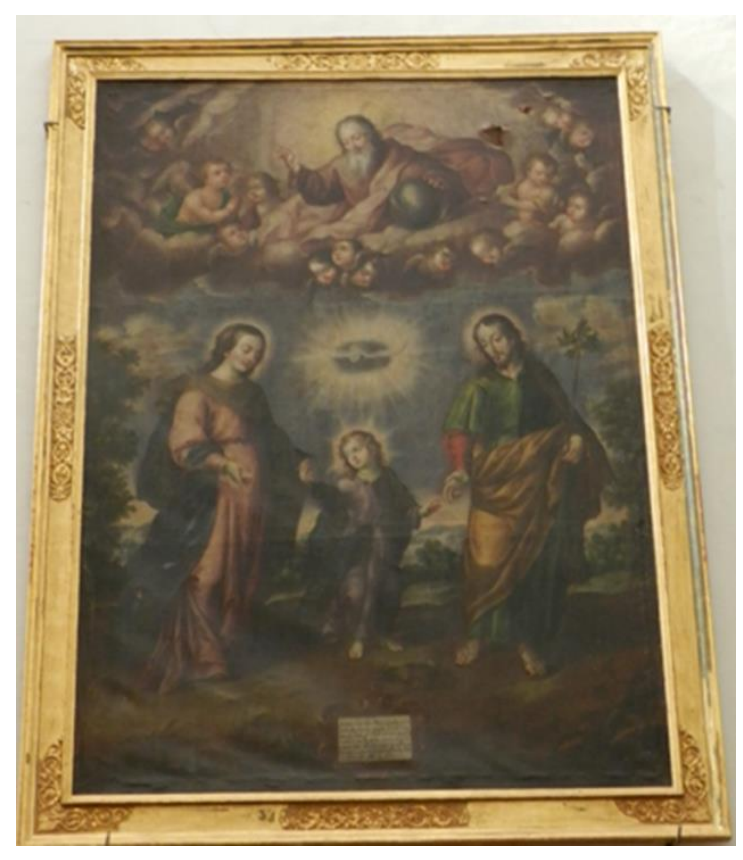

Imagen 4. Juan Sánchez Salmerón (Atribuida). La Sagrada Familia. Óleo sobre lienzo. $345 \times 256 \mathrm{~cm}$. S. XVII. Crucero de la Catedral de

Tulancingo.

Estas pinturas continúan siendo estudiadas por la autora de este texto, se está realizando la búsqueda de documentos en distintos archivos históricos para corroborar tanto la autoría como la pertenencia de estas dos obras.

Nada más parece haber sobrevivido al tiempo, sin embargo, si se mira con cuidado, la huella de esta familia está en muchos de los ranchos y haciendas de los alrededores, en ellos han dejado la impronta de sus devociones y su forma de vida.

Las propiedades rurales vinculadas al mayorazgo tenían una extensión de 741 kilómetros cuadrados en tierras de pan llevar. Doris Ladd señala que las tierras del conde se extendían desde el actual estado de Veracruz hacia Puebla y Tlaxcala por el noroeste, llegaban hasta estancias ganaderas localizadas más allá de las minas de Pachuca, poseían extensas plantaciones magueyeras alrededor de la capital, continuaban en el valle de Tulancingo en sus haciendas pulqueras y terminaban en el actual estado de Morelos formando una media luna que comienza y remata en plantaciones de azúcar. Muchos de los nombres de las haciendas y ranchos han sobrevivido al paso del tiempo y todavía reconocemos los nombres de Alcholoya, la Cueva, Tepenacasco, Santa María Tecajete, Hueyapan, San Nicolás Jaltlaco...

Dos descendientes de Graciana de Acuña y Jaso llevaron también su nombre, una de ellas se encargó de la reconstrucción de la casa de la calle de la calle de San Francisco en la ciudad de México, la cual vistió de azulejos.

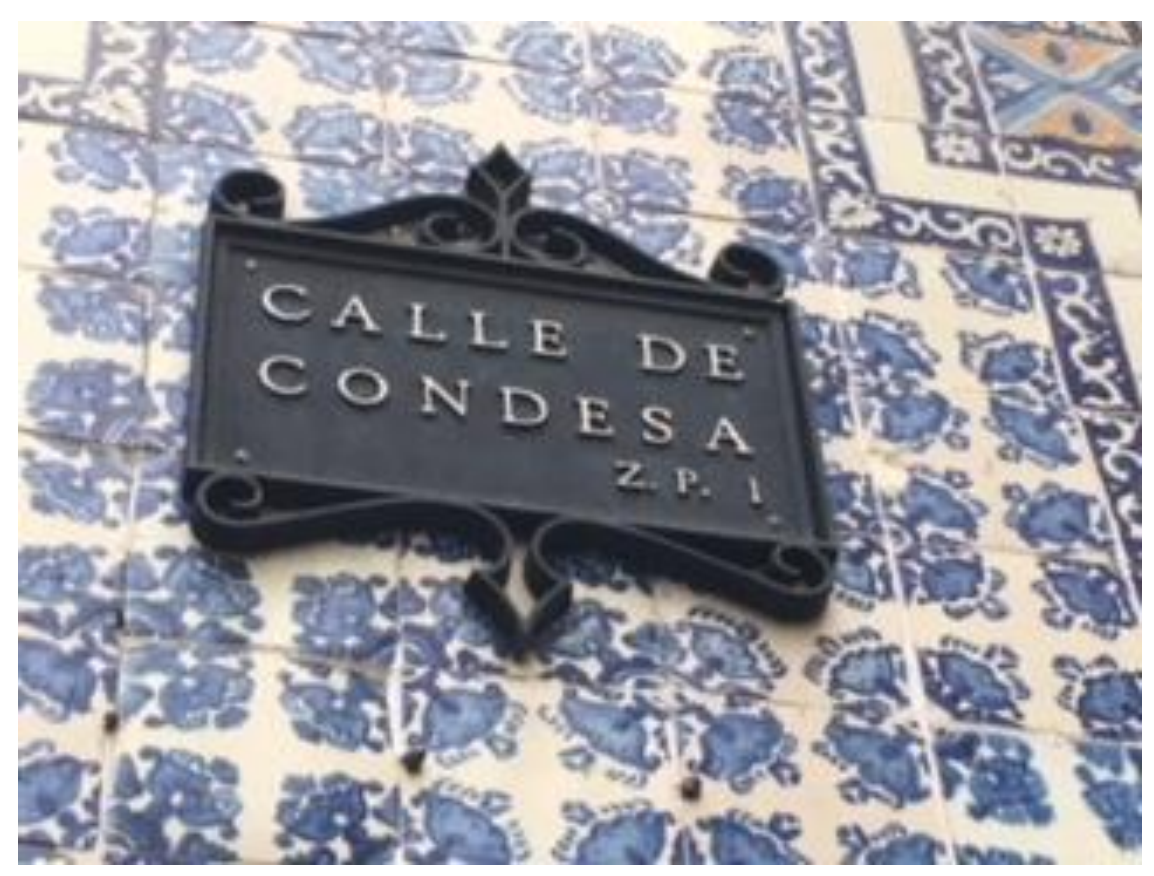

Imagen 5. Azulejos 


\section{Referencias}

Aguirre Beltrán, G. (1989). "La Hacienda más grande de azúcares”, Orizaba, nobles criollos, negros esclavos e indios de repartimiento. México: Universidad Veracruzana. http://cdigital.uv.mx/handle/123456789/1972. Recuperado 1 de junio, 2018.

Conde y Díaz Rubín, J.I. y Sánchiz Ruiz, J. (2012). Historia Genealógica de los títulos y dignidades nobiliarias de la Nueva España y México. México: UNAM.

Fernández de Recas, G. (1965). Mayorazgos de la Nueva España. México: UNAM.

Gonzalvo Aizpuru, P. (2005). Historia de la Vida Cotidiana en México. III Entre Tradición y cambio. México: FCE.

Rubial García, A. (2005). Historia de la Vida Cotidiana en México. II La ciudad barroca. México, FCE.

Sánchiz Ruiz, J. (2017). El Condado del Valle de Orizaba a través de sus mujeres. México: IIH, UNAM. 